\title{
Biodegradation and Biocompatibility of Poly L-lactic Acid Implantable Mesh
}

\author{
Sang-Don Yoon ${ }^{1, *}$, Young-Sam Kwon ${ }^{2, *}$, Kyu-Sung Lee ${ }^{1,3}$ \\ ${ }^{1}$ Department of Medical Device Management \& Research, SAIHST, Sungkyunkwan University, Seoul, Korea \\ ${ }^{2}$ Department of Veterinary Surgery, College of Veterinary Medicine, Kyungpook National University, Daegu, Korea \\ ${ }^{3}$ Department of Urology, Samsung Medical Center, Sungkyunkwan University School of Medicine, Seoul, Korea
}

Purpose: The purpose of this study was to evaluate the biodegradation and biocompatibility of poly L-lactic acid (PLLA) implantable mesh under in vitro and in vivo conditions.

Methods: PLLA mesh was examined for changes in weight and tensile strength. The histology of the tissue around the PLLA implant was also evaluated.

Results: The weight and tensile strength of the PLLA prosthesis was stable for 180 days. In addition, the surface of the PLLA mesh was not digested under in vitro or in vivo conditions as determined by scanning electron microscope. Histologically, there were no significant changes in the diameters of implanted PLLA mesh and subtype fibers over the course of 180 days. Likewise, there were no significant changes in the number of inflammatory and mast cells after 180 days, nor was there an increase in the percentage of collagen surrounding the PLLA mesh.

Conclusions: The results indicate that PLLA prostheses have good rigidity and biocompatibility in vivo and in vitro.

Keywords: Biodegradation; Biocompatibility; Polylevolactic acid; Mesh

- Fund/Grant Support: This study was funded by technology development project s2274204 of the Small and Medium Business Administration. This study was supported by the Korea Health Technology R\&D Project; Ministry of Health and Welfare, Republic of Korea (grant numbers: HI14C3229, HI10C2020).

- Research Ethics: The procedures in this study were approved by the Institutional Animal Care and Use Committee of Kyungpook National University (2016-0086).

- Conflict of Interest: No potential conflict of interest relevant to this article was reported.

\section{- HIGHLIGHTS}

- The tensile strengths of PLLA mesh were not decreased after in vitro incubation for 180 days.

- The diameter of PLLA fibers was unchanged in vitro and in vivo as assessed by SEM and histological examination.

- PLLA mesh did not induce inflammation in subcutaneous tissue.

\section{INTRODUCTION}

Various types of scaffolds have been developed for both research and clinical applications of skin tissue engineering [1-3].
For example, synthetic biodegradable polymers such as poly Llactic acid (PLLA) and poly(glycolic acid) (PGA) have been used to prepare porous scaffolds for skin reconstruction $[4,5]$. A requirement of such scaffolds is mechanical strength, which
Corresponding author: Kyu-Sung Lee (iD http://orcid.org/0000-0003-0891-2488 Department of Urology, Samsung Medical Center, Sungkyunkwan University, School of Medicine, 81 Irwon-ro, Gangnam-gu, Seoul 06351, Korea

E-mail: ksleedr@skku.edu / Tel: +82-2-3410-3559 / Fax: +82-2-3410-3027

*Sang-Don Yoon and Young-Sam Kwon contributed equally to this study as cofirst authors.

Submitted: March 15, 2017 / Accepted after revision: April 7, 2017 
is necessary to maintain the structure and shape for implantation. The characteristics of an ideal implant material have been defined, and include biocompatibility, sufficient mechanical strength, physical resistance to the surrounding tissue, and availability in a convenient format that is also affordable for clinical use [6,7].

Lactic acid-based polymers (PLA) are degraded at a slower rate than lactic acid-glycolic acid copolymers. PLLA mesh is more resistant to degradation, and its tensile strength can be long-lasting, up to 8 months [8,9]. PLLA also exhibits better biocompatibility and produces a lower inflammatory response compared to polypropylene (PPL), a reference nonabsorbable material [10]. L-lactic acid-rich PLA-based materials have been used for more than 10 years in orthopedic surgery, where they have gained a reputation for good biocompatibility in applications such as bone fixation, bone substitutes, and repair of osteochondral defects, ligaments, and tendon reconstructions $[11,12]$. Recently, PLLA stents have also been studied in cardiovascular surgery applications [13].

Biodegradable mesh for skin plastic surgery should not only be able to support the tension applied to the tissue, but also inhibit any inflammatory responses that occur at the site of implantation. PLLA is a good candidate for such artificial subcutaneous prostheses, owing to its high bio-compatibility and favorable biophysical properties.

The goal of this study was to characterize biodegradable PLLA small-diameter artificial prostheses for skin plastic surgery and to assess their biocompatibility in subcutaneous tissue. In vitro studies were carried out either in the presence of lysozyme or phosphate buffer saline (PBS). In addition, the biocompatibility of a PLLA prosthesis was evaluated over the course of 180 days using a subcutaneous rat model.

\section{MATERIALS AND METHODS}

\section{Preparation of PLLA Mesh}

A PLLA cylindrical mesh implant was provided by Prestige Medicare Co., Ltd (Raise Me Up, Seongnam, Korea). The product was $\Phi 0.8 \times 300 \mathrm{~mm}$ in size, and its purpose is to support or protect soft tissue by acting as a biodegradable polymeric surgical mesh.

\section{In Vitro Degradation of PLLA Prosthesis}

For the degradation test, the PLLA mesh $(\Phi 0.8 \times 50 \mathrm{~mm})$ was first weighed and then placed in sealed polyethylene bottles filled with PBS in the presence of 50 units $/ \mathrm{mL}$ of lysozyme at $37^{\circ} \mathrm{C}, \mathrm{pH} 7.2$ for $30,60,90,120,150$, and 180 days $(\mathrm{n}=5)$. At specific time points, the specimens were washed thoroughly with deionized water and dried at $50^{\circ} \mathrm{C}$ in an oven for 12 hours. Finally, the samples were weighed and prepared for scanning electron microscopy.

\section{In Vivo Study}

Thirty male Sprague-Dawley rats (250-300 g) were anesthetized with xylazine and ketamine prior to abdominal skin implantation of the biodegradable PLLA prosthesis. Two mesh implants with dimensions of $\Phi 0.8 \times 50 \mathrm{~mm}$ were placed in the abdominal subcutaneous tissue of each rat via 2 small holes parallel to the midline. Rats were sacrificed with anesthesia and cervical dislocation at $30,60,90,120,150$, and 180 days after implantation. Tissue samples impregnated with PLLA mesh were taken from the left side of the abdomen and fixed with $10 \%$ neutral formalin for histological examination. On the right side, PLLA mesh was separated from the subcutaneous tissue, wiped with gauze, and prepared for scanning electron microscopy and analysis of tensile strength. The procedures in this study were approved by the Institutional Animal Care and Use Committee of Kyungpook National University (2016-0086).

\section{Evaluation for Tensile Strength of PLLA Mesh}

The tensile strength of the PLLA mesh explanted from the abdominal skin tissue was measured with a tensiometer (JSVH1000, JISC Ltd., Tokyo, Japan). The mesh was secured tightly in a clamp in order to prevent slipping during the test, and measurements were performed at a rate of $30 \mathrm{~mm}$ per minute. The tensiometer was used to measure the breakage strength of specimens, and all analyses were performed at room temperature.

\section{Scanning Electron Microscopy}

The PLLA mesh specimens were washed in PBS (pH, 7.2) and fixed in $2.5 \%$ glutaraldehyde overnight prior to dehydration in increasing concentrations of ethanol (30\%, 50\%, 70\%, 90\%, $95 \%$, and $100 \%, 1$ hour each). The samples were then dried with critical point drying. The dried specimens were coated with gold before being observed under a scanning electron microscope (SEM) to investigate the surface morphology at the lumen of the prosthesis.

\section{Histological Staining}

The skin samples were fixed in $10 \%$ neutral buffered formalin 
for 24 hours and then prepared as paraffin blocks. Sections 3-4 $\mu \mathrm{m}$ thick were subsequently prepared, and representative sections were stained with hematoxylin and eosin for general histopathology, Masson's trichrome (MT) stain for collagen fiber, and Toluidine blue (TB) stain for mast cells according to previously established methods [14-17]. The stained histological sections were observed by light microscopically (Model Eclipse 80i, Nikon, Tokyo, Japan). For analysis of more detailed changes, the diameter of PLLA bundles and subtype fibers were measured. In addition, the number of inflammatory cells and mast cells around PLLA bundles was counted. The percentage of collagen fiber around PLLA bundles was calculated by histomorphometrical analysis using a computer-assisted image analysis program (iSolution FL ver 9.1, IMT i-solution Inc., Vancouver, BC, Canada) as described previously [14-17] with some modifications.

\section{Statistical Analysis}

All data are expressed as the mean \pm standard deviation. Data were statistically evaluated by paired Student $t$-test. P-values less than 0.05 were considered statistically significant.

\section{RESULTS}

\section{Weight of PLLA Implants In Vitro}

After digestion with lysozyme in vitro, the weight of the PLLA implants were $0.0100 \pm 0.00017 \mathrm{~g}$ (day 0 , before), $0.0103 \pm$ $0.00021 \mathrm{~g}$ (day 30), $0.0102 \pm 0.00025 \mathrm{~g}$ (day 60), $0.0109 \pm$ $0.00074 \mathrm{~g}$ (day 90), $0.0100 \pm 0.00051 \mathrm{~g}$ (day 120), $0.0104 \pm$ $0.00047 \mathrm{~g}$ (day 150), and $0.0102 \pm 0.00033 \mathrm{~g}$ (day 180). There were no significant differences in the weights of PLLA mesh

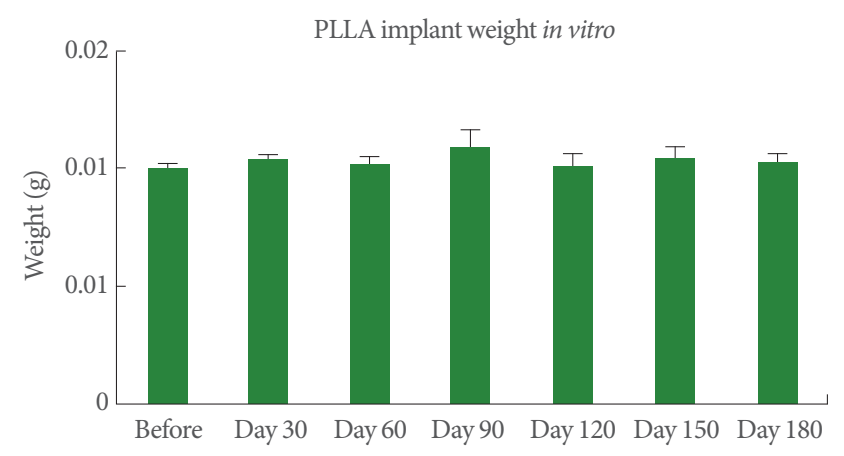

Fig. 1. Poly L-lactic acid (PLLA) implant weight according to incubation time. The weight of the PLLA implant was measured after digestion for $30,60,90,120,150$, and 180 days in phosphate buffer saline with lysozyme. compared to weight at the initial (day 0) time point (Fig. 1).

\section{The Tensile Strength of PLLA Mesh}

The tensile strengths of the PLLA mesh were $29.87 \pm 2.03 \mathrm{~N}$ (day 0), $29.63 \pm 4.61 \mathrm{~N}$ (day 30), $25.17 \pm 9.59 \mathrm{~N}$ (day 60), 26.70 $\pm 3.68 \mathrm{~N}$ (day 90), $26.23 \pm 6.77 \mathrm{~N}$ (day 120), $28.59 \pm 7.10 \mathrm{~N}$ (day 150 ), and $27.51 \pm 4.33 \mathrm{~N}$ (day 180). There were no significant changes in the tensile strength for each time point compared with the initial (day 0) time point (Fig. 2). These results suggest that the PLLA mesh maintains its strength in soft tissue for 180 days.

\section{Scanning Electron Microscopy}

SEM observation of the PLLA prostheses after 180 days showed that the surface was not digested in vitro, and had a similar shape as the implant prior to digestion. The surface of in vivo PLLA implants was not able to be examined due to ingrowth of the tissue around the mesh fiber. However, the PLLA mesh fibers did appear to maintain their diameter compared to preimplantation specimens (Fig. 3).

\section{Histological Findings}

The diameters of the PLLA mesh implants were $566.62 \pm 22.19$ $\mu \mathrm{m}$ (day 30), $563.42 \pm 21.83 \mu \mathrm{m}$ (day 60), $570.95 \pm 26.69 \mu \mathrm{m}$ (day 90), $564.30 \pm 18.50 \mu \mathrm{m}$ (day 120), $562.71 \pm 21.32 \mu \mathrm{m}$ (day 150 ), and $558.53 \pm 13.34 \mu \mathrm{m}$ (day 180). The diameters of the PLLA subtype fibers were $151.01 \pm 9.12 \mu \mathrm{m}$ (day 30), $150.44 \pm$ $9.40 \mu \mathrm{m}$ (day 60), $150.92 \pm 3.81 \mu \mathrm{m}$ (day 90), $153.32 \pm 9.35 \mu \mathrm{m}$ (day 120), $153.76 \pm 4.16 \mu \mathrm{m}$ (day 150), and $153.32 \pm 8.94 \mu \mathrm{m}$ (day 180). The number of inflammatory cells around the PLLA mesh was $85.40 \pm 35.66$ (day 0), $85.20 \pm 54.27$ (day 30),

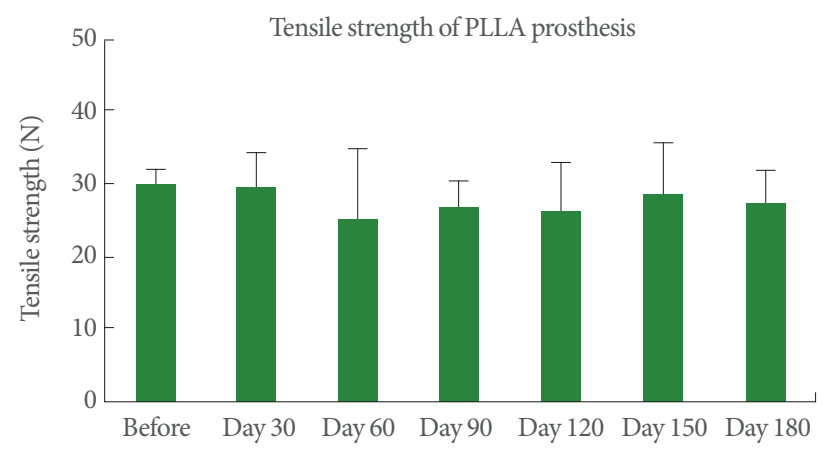

Fig. 2. The tensile strength of poly L-lactic acid (PLLA) implants was measured after tissue implantation for $30,60,90,120,150$, and 180 days. 


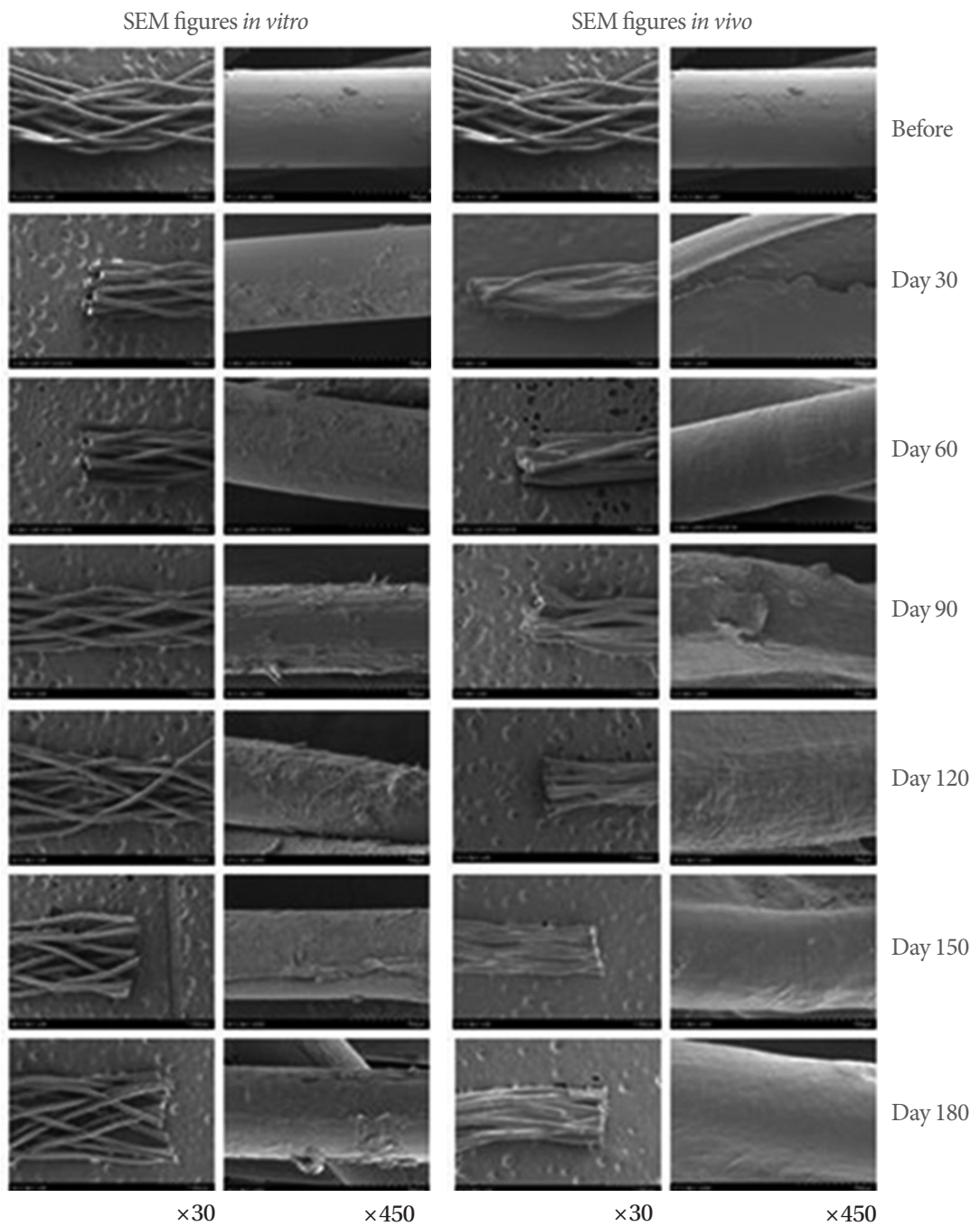

Fig. 3. Scanning electron microscopy. Samples were collected at the indicated time points and observed by scanning electron microscope (SEM) to collect information on physical aspects of the mesh and identify any changes in fiber surfaces and sections.

Table 1. Histomorphometrical analysis on the tissue around PLLA subcutaneous implantation

\begin{tabular}{|c|c|c|c|c|c|}
\hline \multirow{2}{*}{ Time } & \multicolumn{2}{|c|}{ Diameter of implanted PLLA } & \multicolumn{3}{|c|}{ Tissue adjacent to PLLA implantation } \\
\hline & Bundles $(\mu \mathrm{m})$ & Subtype fibers $(\mu \mathrm{m})$ & Inflammatory cells (cells $/ \mathrm{mm}^{2}$ ) & Mast cells (cells $/ \mathrm{mm}^{2}$ ) & Collagen fibers $\left(\% / \mathrm{mm}^{2}\right)$ \\
\hline Day 0 & NC & NC & $85.40 \pm 35.66$ & $45.60 \pm 12.20$ & $75.20 \pm 3.93$ \\
\hline Day 30 & $566.62 \pm 22.19$ & $151.01 \pm 9.12$ & $85.20 \pm 54.27$ & $42.80 \pm 7.82$ & $74.88 \pm 9.00$ \\
\hline Day 60 & $563.42 \pm 21.83$ & $150.44 \pm 9.40$ & $96.60 \pm 50.45$ & $41.80 \pm 7.50$ & $74.15 \pm 6.52$ \\
\hline Day 90 & $570.95 \pm 26.69$ & $150.92 \pm 3.81$ & $90.60 \pm 39.15$ & $38.40 \pm 10.04$ & $74.59 \pm 3.39$ \\
\hline Day 120 & $564.30 \pm 18.50$ & $153.32 \pm 9.35$ & $82.60 \pm 17.40$ & $43.60 \pm 14.03$ & $73.25 \pm 4.46$ \\
\hline Day 150 & $562.71 \pm 21.32$ & $153.76 \pm 4.16$ & $89.80 \pm 27.11$ & $43.20 \pm 8.44$ & $73.10 \pm 5.93$ \\
\hline Day 180 & $558.53 \pm 13.34$ & $153.32 \pm 8.94$ & $88.20 \pm 14.86$ & $40.00 \pm 2.00$ & $74.29 \pm 6.06$ \\
\hline
\end{tabular}

Values are presented as mean \pm standard deviation.

PLLA, poly L-lactic acid; NC, not calculated. 


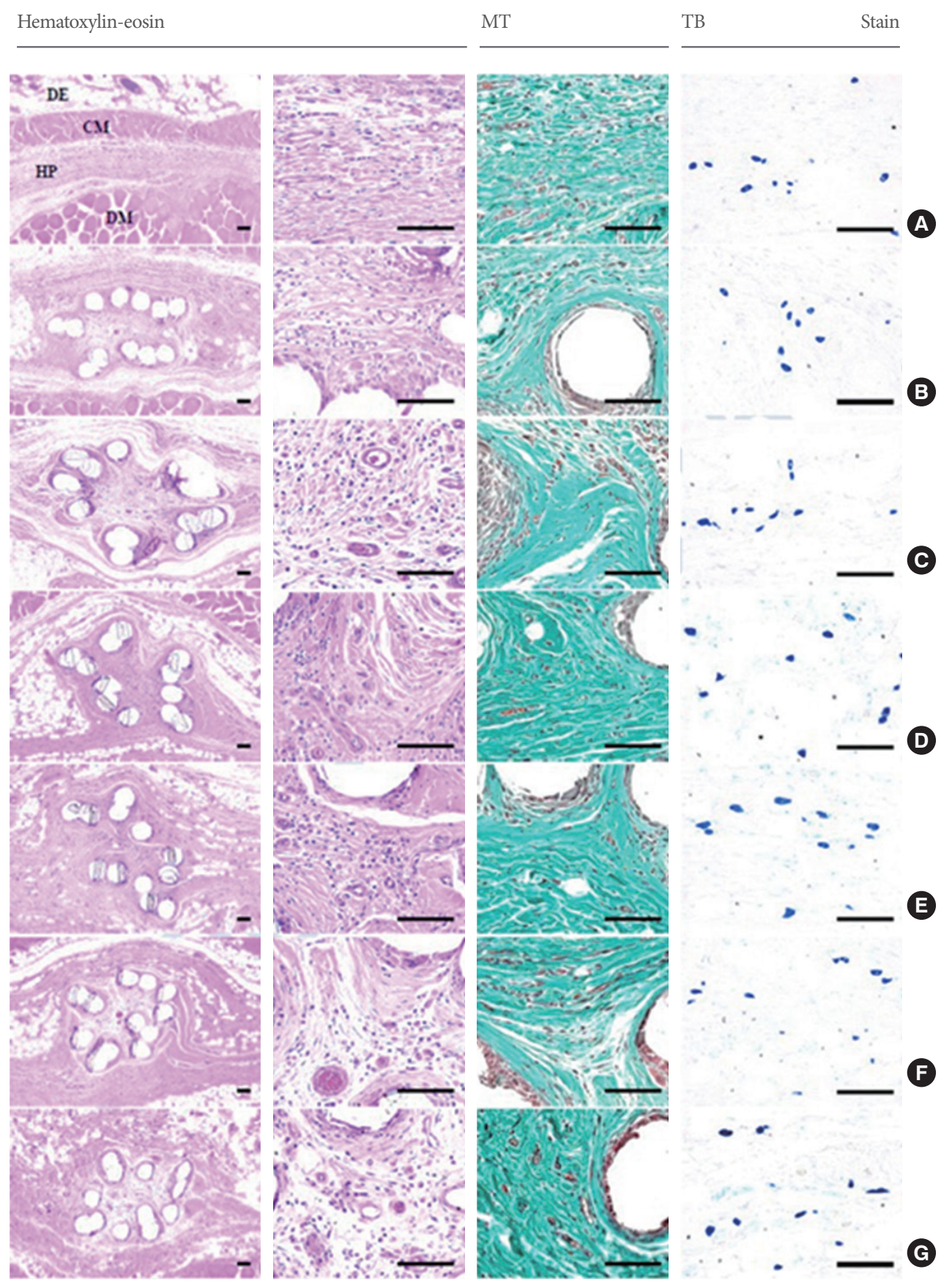

Fig. 4. Representative histopathological images of subcutaneous tissues surrounding poly L-lactic acid (PLLA) implants. The PLLA mesh consisted of 12 subtype fibers, all of which were present at each time point of 30, 60, 90, 120, 150, and 180 days. There were no significant changes in the diameters of the implanted PLLA mesh or subtype fibers at 60, 90, 120, 150, and 180 days after implantation. In addition, there were no significant changes in the number of inflammatory and mast cells, and the percentage of collagen around PLLA mesh remained stable over 180 days. (A) Normal control (day 0). (B) Tissue collected 30 days after PLLA implantation (day 30 ). (C) Tissue collected 60 days after PLLA implantation (day 60). (D) Tissue collected 90 days after PLLA implantation (day 90). (E) Tissue collected 120 days after PLLA implantation (day 120). (F) Tissue collected 150 days after PLLA implantation (day 150). (G) Tissue collected 180 days after PLLA loading (day 180). CM, cutaneous muscle; DM, dorsal back muscle; DE, dermis; HP, hypodermis; MT, Masson's trichrome; TB, Toluidine blue. Scale bars $=80 \mu \mathrm{m}$. 
$96.60 \pm 50.45$ (day 60), $90.60 \pm 39.15$ (day 90), $82.60 \pm 17.40$ (day 120 ), $89.80 \pm 27.11$ (day 150), $88.20 \pm 14.86$ (day 180). Likewise, the number of mast cells around the PLLA mesh was $45.60 \pm 12.20$ (day 0), $42.80 \pm 7.82$ (day 30), $41.80 \pm 7.50$ (day 60), $38.40 \pm 10.04$ (day 90), $43.20 \pm 8.44$ (day 120), $43.20 \pm 8.44$ (day 150), and $40.00 \pm 2.00$ (day 180). Lastly, the percentage of collagen fibers in the tissue was $75.20 \% \pm 3.93 \%$ (day 0 ), $74.88 \% \pm 9.00 \%$ (day 30 ), $74.15 \% \pm 6.52 \%$ (day 60 ), $74.59 \% \pm 3.39 \%$ (day 90 ), $73.25 \% \pm$ $4.46 \%$ (day 120), $73.10 \% \pm 5.93 \%$ (day 150 ), and $74.29 \% \pm 6.06 \%$ (day 180) (Table 1, Fig. 4).

The PLLA mesh contained 12 fiber subtypes at each of the time points analyzed. There were no significant changes in the diameters of the implanted PLLA mesh and subtype fibers for samples collected at $60,90,120,150$, or 180 days postimplantation. In addition, there were no significant changes in the number of inflammatory or mast cells or percentage of collagen abundance around the PLLA mesh at 180 days (Fig. 4).

\section{DISCUSSION}

Among various scaffold materials, collagen and gelatin are commonly used to prepare scaffolds due to their favorable intrinsic properties such as low antigenicity and ability to promote cell adhesion and proliferation [18]. However, collagen and gelatinbased scaffolds have a low mechanical strength, meaning that they are rapidly absorbed in tissue. For these reasons, various alternative scaffolds of biodegradable synthetic polymers have been developed, such as PLLA, PGA, poly(lactic-co-glycolic acid), and poly( $\varepsilon$-caprolactone), which have favorable mechanical and biocompatible properties [4,5].

PLLA has been widely studied for bone regeneration due to its degradability, biocompatibility, and process ability [19-21]. However, there are several aspects of PLLA that remain problematic with respect to its application in biomedical fields, including hydrophobicity, lack of bioactivity, and release of acidic degradation by-products that may cause inflammation when implanted in vivo [22,23]. In the present study, in vitro and in vivo studies were used to determine whether PLLA mesh, when used as a subcutaneous implantable scaffold for plastic surgery, undergoes mechanical and biocompatible changes.

It was found that the weight and microstructure of PLLA were not significantly altered during in vitro experiments. In addition, PLLA fibers were not digested by lysozyme after 180 days as determined by SEM. This result is consistent with the findings of de Tayrac et al. [10], who observed degradation of
PLLA mesh only after 8 months at a $\mathrm{pH}$ of 7.4 and temperature of $37^{\circ} \mathrm{C}$. In vivo implantation experiments were also performed to evaluate the biocompatibility of PLLA mesh, as well as to determine whether PLLA mesh is biodegraded or becomes weakened with respect to mechanical strength after prolonged implantation.

Under in vitro conditions, the tensile strengths of the PLLA mesh did not decrease after 180 days. Consistent with this finding, a previous study showed that the tensile strength of a PLLA scaffold developed for vaginal surgery begins to decrease under $20 \mathrm{~N}$ of force only after implantation for 8 months [10]. In addition, this study found that the diameter of PLLA fibers did not decrease during the experiments as determined by SEM and histological examination. These findings suggested that the PLLA mesh used in the present study was not digested in living tissue.

Histological examination showed that there were no significant time-dependent changes in the number of inflammatory and mast cells induced by the implanted PLLA mesh. Likewise, there were no changes in the percentage of collagen fibers in subcutaneous tissue around the PLLA mesh during experiments. Conversely, it has been reported that PLLA may induce an inflammatory reaction due its hydrophobicity, low bioactivity, and release of acidic degradation by-products in musculoskeletal tissue and in vitro when incubated with gastric juice $[22,23]$. Taken together with the results of this study, PLLA mesh may not cause inflammation in subcutaneous tissue, but may cause inflammation in other tissues or under specific incubation conditions.

In summary, by using in vitro and in vivo models, the current study showed that the weight and microstructure of PLLA is not degraded over time. Specifically, the tensile strengths of PLLA mesh did not decrease after in vitro incubation for 180 days. In addition, the diameter of PLLA fibers was unchanged in vitro and in vivo during the study period as assessed by SEM and histological examination. The PLLA mesh did not induce inflammation in subcutaneous tissue; however, according to the literature, it may cause inflammation in different tissues or under specific incubation conditions. Therefore, PLLA mesh may be very useful as a subcutaneous implantable device for skin plastic surgery. Future studies on long term application of PLLA mesh in the subcutaneous space will be useful to more clearly determine the biodegradable and biocompatible properties of PLLA. 


\section{REFERENCES}

1. Bello YM, Falabella AF, Eaglstein WH. Tissue-engineered skin. Current status in wound healing. Am J Clin Dermatol 2001;2:30513.

2. Piccirillo G, Bochicchio B, Pepe A, Schenke-Layland K, Hinderer S. Electrospun poly-l-lactide scaffold for the controlled and targeted delivery of a synthetically obtained Diclofenac prodrug to treat actinic keratosis. Acta Biomater 2017;52:187-96.

3. Yu J, Huang TR, Lim ZH, Luo R, Pasula RR, Liao LD, et al. Production of hollow bacterial cellulose microspheres using microfluidics to form an injectable porous scaffold for wound healing. Adv Healthc Mater 2016;5:2983-92.

4. Cooper ML, Hansbrough JF, Spielvogel RL, Cohen R, Bartel RL, Naughton G. In vivo optimization of a living dermal substitute employing cultured human fibroblasts on a biodegradable polyglycolic acid or polyglactin mesh. Biomaterials 1991;12:243-8.

5. Yang WS, Roh HW, Lee WK, Ryu GH. Evaluation of functions and tissue compatibility of poly (D,L-lactic-co-glycolic acid) seeded with human dermal fibroblasts. J Biomater Sci Polym Ed 2006;17: 151-62.

6. Desai VB. Marlex mesh prosthesis for massive vaginal vault prolapse. Int Surg 1987;72:160-2.

7. Ignatius AA, Claes LE. In vitro biocompatibility of bioresorbable polymers: poly(L, DL-lactide) and poly(L-lactide-co-glycolide). Biomaterials 1996;17:831-9.

8. Grizzi I, Garreau H, Li S, Vert M. Hydrolytic degradation of devices based on poly(DL-lactic acid) size-dependence. Biomaterials 1995;16:305-11.

9. Vert M, Schwach G, Engel R, Coudane J. Something new in the field of PLA/GA bioresorbable polymers? J Control Release 1998; 53:85-92.

10. de Tayrac R, Chentouf S, Garreau H, Braud C, Guiraud I, Boudeville $\mathrm{P}$, et al. In vitro degradation and in vivo biocompatibility of poly(lactic acid) mesh for soft tissue reinforcement in vaginal surgery. J Biomed Mater Res B Appl Biomater 2008;85:529-36.

11. Merloz P, Minfelde R, Schelp C, Lavaste F, Huet-Olivier J, Faure C, et al. In vitro study of the properties of bioresorbable lactic acid polymer materials. Rev Chir Orthop Reparatrice Appar Mot 1995; 81:433-44

12. Athanasiou KA, Niederauer GG, Agrawal CM. Sterilization, toxici- ty, biocompatibility and clinical applications of polylactic acid/ polyglycolic acid copolymers. Biomaterials 1996;17:93-102.

13. Tamai H, Igaki K, Kyo E, Kosuga K, Kawashima A, Matsui S, et al. Initial and 6-month results of biodegradable poly-l-lactic acid coronary stents in humans. Circulation 2000;102:399-404.

14. Lee HS, Cho HR, Yang KJ, Shin HD, Park BR, Jang HJ, et al. Local irritation test of 3 types of $\beta$-glucan after subcutaneous injection in rats. Lab Anim Res 2006;22:339-42.

15. Drynda A, Seibt J, Hassel T, Bach FW, Peuster M. Biocompatibility of fluoride-coated magnesium-calcium alloys with optimized degradation kinetics in a subcutaneous mouse model. J Biomed Mater Res A 2013;101:33-43.

16. Kim CG, Kang M, Lee YH, Min WG, Kim YH, Kang SJ, et al. Bathing effects of various seawaters on allergic (atopic) dermatitis-like skin lesions induced by 2,4-dinitrochlorobenzene in hairless mice. Evid Based Complement Alternat Med 2015;2015:179185.

17. Kim KH, Park SJ, Lee YJ, Lee JE, Song CH, Choi SH, et al. Inhibition of UVB-induced skin damage by exopolymers from Aureobasidium pullulans SM-2001 in hairless mice. Basic Clin Pharmacol Toxicol 2015;116:73-86.

18. Cobb WS, Burns JM, Peindl RD, Carbonell AM, Matthews BD, Kercher KW, et al. Textile analysis of heavy weight, mid-weight, and light weight polypropylene mesh in a porcine ventral hernia model. J Surg Res 2006;136:1-7.

19. Zhu A, Zhang M, Wu J, Shen J. Covalent immobilization of chitosan/heparin complex with a photosensitive hetero-bifunctional crosslinking reagent on PLA surface. Biomaterials 2002;23:465765.

20. Goswami J, Bhatnagar N, Mohanty S, Ghosh AK. Processing and characterization of poly(lactic acid) based bioactive composites for biomedical scaffold application. Express Polym Lett 2013;7:767-77.

21. Li D, Sun H, Jiang L, Zhang K, Liu W, Zhu Y, et al. Enhanced biocompatibility of PLGA nanofibers with gelatin/nano-hydroxyapatite bone biomimetics incorporation. ACS Appl Mater Interfaces 2014;6:9402-10

22. Li H, Chang J. Preparation and characterization of bioactive and biodegradable wollastonite/poly(D,L-lactic acid) composite scaffolds. J Mater Sci Mater Med 2004;15:1089-95.

23. Chang H, Huang CC, Tsai HC, Imae T, Hong PD. Characterization and morphology analysis of degradable poly(L-lactide) film in in vitro gastric juice incubation. Appl Surf Sci 2012;262:89-94.VV 